\title{
Lesions of the medial medullary reticular area in rats impair CER acquisition
}

\author{
GEOFFREY R. HAMMOND \\ University of Western Australia, Nedlands, Western Australia, Australia
}

\begin{abstract}
Rats with surgical damage to the midline reticular area of the medulla were impaired in acquisition of a conditioned emotional response relative to operated controls. This result shows that the brain-damaged animals were deficient in perception of pain-related information, which would suggest that there is an important sector of the ascending pain system in the midline area of the medulla.
\end{abstract}

There is widespread agreement that the medial reticular formation (RF) of the lower brainstem in the rat and cat, especially the region of nucleus reticularis gigantocellularis, is involved in some fashion in reaction to noxious stimulation. This conclusion is pointed to by three lines of evidence: First, damage to this region is followed by lowered reactivity to noxious stimulation (Anderson \& Pearl, 1978, cited in Fields \& Basbaum, 1978; Halpern \& Halverson, 1974); second, electrophysiological recording has shown that units within the medial medullary and pontine region respond maximally or solely to noxious stimulation (e.g., Casey, 1969, 1971; Goldman, Collins, Taub, \& Fitzmartin, 1972; Segundo, Takenaka, \& Encabo, 1967); and third, electrical stimulation of the region elicits escape and other aversive behaviors (Casey, 1971; Keene \& Casey, 1970). This evidence, however, does not answer the question of whether the medial medullary RF, which is a source of long ascending and descending fibers (Brodal, 1957), is involved primarily as part of ascending sensory system that is responsive to noxious stimuli or as part of a descending motor control system associated with aversive and agonistic behavior. Most have taken the view that the medial reticular area forms part of an ascending "pain transmission" system (e.g., Fields, Wagner, \& Anderson, 1975; Halpern \& Halverson, 1974; Melzack \& Casey, 1968). Recently, some have taken the position that the primary involvement of the medial reticular area of the lower brainstem is motor. Siegel and McGinty (1977) reported that both spontaneous and driven electrophysiological responses of cells in this area were more closely related to motor output than to sensory input. Furthermore, they found that there was a rapid decrement of driven cellular activity and that this response decrement was correlated with decrement of behavioral response. In

I thank L. Fechter and Z. Annau of the Division of Toxicology of Johns Hopkins University for their assistance in completing this work and P. Meyer of the University of Western Australia for doing the histological work. This research was supported by a grant from the ARGC. a review of the literature on reticulospinal projections, Peterson (1979) similarly argued for an involvement of the medial pontine and medullary reticular formation in movement control. Peterson's argument was based on, first, anatomical evidence of direct connections from this reticular region to spinal motoneurons, and second, physiological evidence of rapid decrement of response of cells in this region to repeated stimulation. This rapid response habituation was seen to be inconsistent with a role as an important afferent relay.

The behavioral effects of lesions placed within the lower brainstem reticular formation could help to resolve this issue. While lesions placed within the RF reduce reactivity to noxious stimuli, as noted above, this could result either from a postsurgical impairment of the appreciation of pain or from a deficit in the behavioral reaction to the noxious events. It should be possible to differentiate these possibilities by testing animals with RF lesions on a task based on aversive motivation, such as conditioned suppression. If the lesions disturbed only the expression of aversion, it would still be possible to condition the aversive motivational effects of noxious stimulation, that is, the treated animals should acquire conditioned suppression unimpaired relative to intact control animals. Conversely, if such lesions interfered with the processing of pain-related information, there would be a deficit in aversive motivation and, presumably, a corresponding deficit in acquisition of conditioned suppression. Results reported here from animals with damage to the medullary RF support this latter alternative.

\section{METHOD}

\begin{abstract}
Animals
Eleven experimentally naive pigmented rats were used. They were assigned nonsystematically to an experimental group $(n=5)$ or an operated control group $(n=6)$. Subjects were housed individually and had continuous access to food. Access to water was restricted to $10 \mathrm{~min}$ following training during the behavioral testing phase. The animals weighed from 255 to $360 \mathrm{~g}$ at surgery.
\end{abstract}




\section{Apparatus and Procedure}

Surgical. Conventional surgical procedures were used in clean conditions. The animals were anesthetized with $1 \mathrm{ml}$ of Equithesin and secured in a stereotaxic head holder. With the skull level (lambda and bregma adjusted to the same stereotaxic height), the following coordinates were used: $12.5 \mathrm{~mm}$ posterior to bregma; $\pm .5 \mathrm{~mm}$ from the midline; $7.8 \mathrm{~mm}$ below the dorsum of the cerebellum. Bilateral lesions were made in experimental animals by passage of radio-frequency current from a Grass LM3 lesion maker (intensity setting of 75 for $30 \mathrm{sec}$ ). Operated control animals were treated identically except that the electrode was lowered to $1 \mathrm{~mm}$ dorsal to the RF target and no current was passed. Following a transient period of aphagia and adipsia, the brain-damaged subjects appeared to be in good health.

Behavioral. The subjects were first trained to barpress for water reward in a conventional operant chamber located in a soundattenuating box. Stimulus presentation and response recording were under control of a small laboratory computer. The subjects were given 40-min daily training sessions. Barpresses were rewarded according to a probability schedule; beginning with continuous reward $(\mathrm{p}=1.00)$, the probability of a barpress being followed by reward was gradually reduced over days until a terminal probability of .05 was reached. This reward density produced rapid and consistent rates of response in all animals. CER training was begun after stable response rates were reached. All animals received the same amount of training, and there were no group differences in final response levels.

Three daily CER trials were given on 11 consecutive days. On Day 1, no shock was given on any trial in order to habituate orienting to the $\mathrm{CS}$. On the remaining 10 days, the 2-min compound CS (the houselight flashing on and off at $1 / \mathrm{sec}$ together with a $1,500-\mathrm{Hz}$ tone set at $76 \mathrm{~dB})$ terminated in footshock $(.5 \mathrm{sec}$, $.5 \mathrm{~mA}$ ) delivered through the grid floor. A steady background noise level of $70 \mathrm{~dB}$ was provided by a white-noise generator and an exhaust fan. Degree of response suppression was scored as the number of responses made during the CS divided by the sum of responses made during the CS and the immediately preceding 2 -min period. This ratio gives the proportion of CS-related responses made during the total 4-min interval. No response suppression gives a suppression ratio of around .5; with increasing degrees of suppression, the ratio tends towards 0 .

Histological. The animals were killed painlessly and perfused through the heart with physiological saline followed by $10 \%$ Formalin in saline. Following further fixation, the brains were frozen and sectioned serially at $\mathbf{4 0} \mu \mathrm{m}$. Alternate sections through and in the proximity of the lesion were kept and stained for Nissl substance (cresyl violet) and fibers (solochrome cyanin).

\section{RESULTS}

\section{Behavioral}

Mean suppression ratios for the three habituation trials and the 30 CER training trials are shown in Figure 1. No group differences were evident in the habituation phase, but there was a marked difference between the groups in the CER phase $[F(1,9)=12.52$, $\mathrm{p}<.01]$. Furthermore, this group difference became more pronounced with training, as shown by a reliable Groups by Trials interaction $[\mathrm{F}(29,261)=2.91, \mathrm{p}<$ $.01]$. The suppression ratios for each of the six operated control subjects ranged from .07 to .17 , with a mean of .10. One of the brain-damaged group fell within this control range (Subject 1) with a mean suppression ratio across trials of .13. The mean suppression ratios of Subjects $2,3,4$, and 5 were $.28, .34, .47$, and .48 , respectively $(M=.39)$. Thus, one brain-

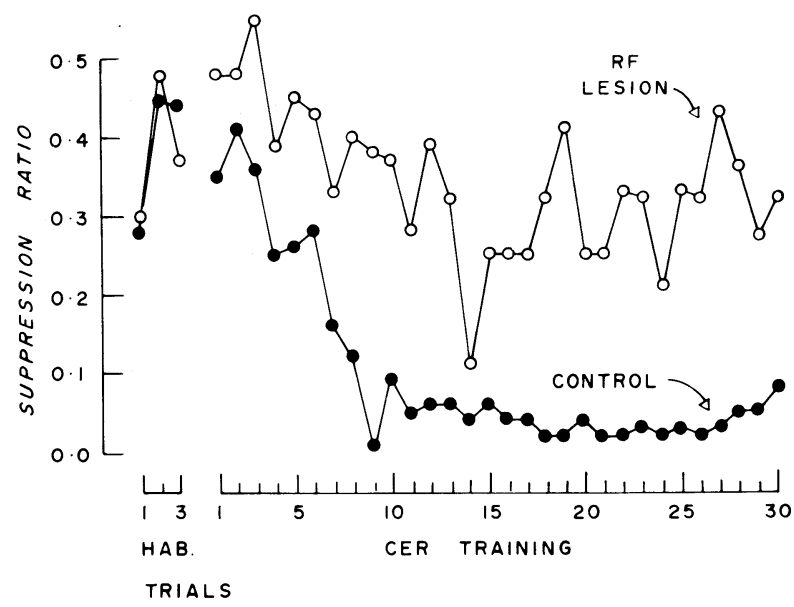

Figure 1. Mean suppression ratios for both groups for the three habituation trials and the 30 CER training trials.

damaged subject showed normal CER acquisition, two (Subjects 2 and 3) were inferior to controls but did show some suppression, and two (Subjects 4 and 5) showed no suppression at all. The absolute response levels of the brain-damaged rats were not below those of the control rats as shown by the average number of responses made during the pre-CS intervals on both the first CER training day (RF lesion group, $M=169$, range $=61-406$; operated control group, $M=162$, range $=128-189$ ) and the last CER training day ( $R F$ lesion group, $M=222$, range $=139-383$; operated control group, $M=138$, range $=80-204$ ).

\section{Histological}

The severity of the behavioral deficit was related directly to the caudal-rostral extent of damage to the medial medulla. In Subject 1, which showed no behavioral deficit, the left- and right-sided lesions were placed asymmetrically in the caudal-rostral plane. As a consequence, the extent of bilateral damage was limited to about $.36 \mathrm{~mm}$. Subjects 2 and 3 both sustained bilateral damage in this region over a caudalrostral extent of about $.84 \mathrm{~mm}$, while Subjects 4 and 5 , which showed the most severe behavioral deficit, suffered bilateral damage over a range of about 1.24 and $1.76 \mathrm{~mm}$, respectively. The behavioral deficit was further related to completeness of damage to the midline region. In both Subjects 4 and 5, there was complete or near-complete destruction of midline tissue from the inferior olive ventrally to the medial longitudinal fasciculus dorsally (Figure 2); the focus of the lesion was somewhat more dorsal in Subject 2 (with consequent sparing of the ventral midline region) and more lateral and ventral in Subject 3 (with sparing of the dorsal midline region). The mediolateral extent of damage was restricted in all animals, with only minor damage to nucleus reticularis gigantocellularis and other parts of the more laterally placed large-celled reticular field (see Figures 2 and 3 ). 

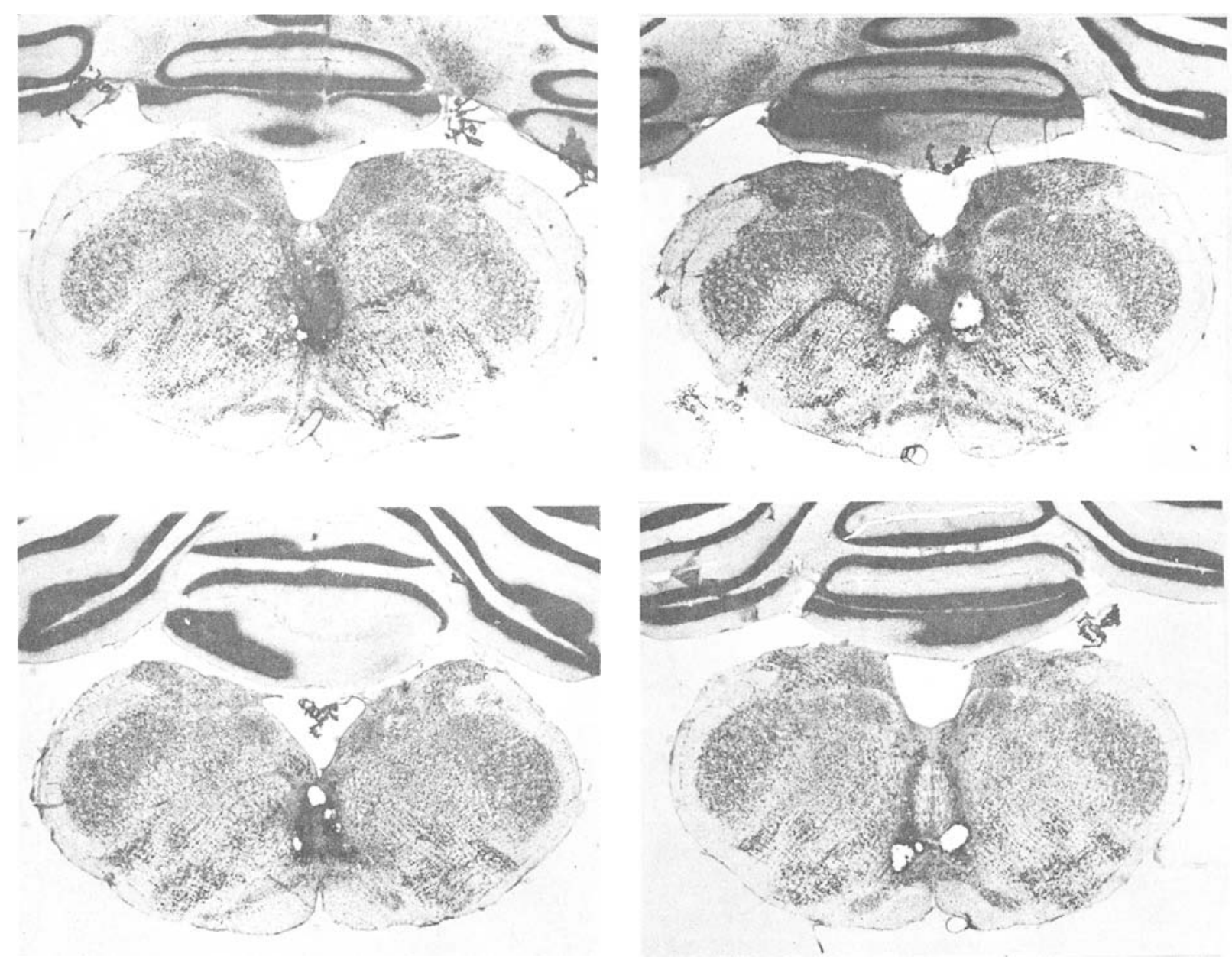

Figure 2. Sections through the greatest extent of the lesion for Subjects 4 (upper panel) and 5 (lower panel).

\section{DISCUSSION}

The behavioral deficit shown by the brain-damaged animals shows that damage to the midline reticular area of rats interrupts an ascending system carrying pain-related information. Four of the five treated animals behaved as if their perception of noxious footshock was impaired or eliminated. Behaviorallyeffective damage was localized medially to the largecelled field of the medulla, and did not appear to include nucleus reticularis gigantocellularis. From these results, disruption of ascending pain-related information was a result of damage to either a midline fiber system or to the midline raphe nuclei (nucleus raphe obscurus and nucleus raphe pallidus described by Valverde, 1962).

The CER procedure is a useful technique for differentiating the effects of damage to ascending and descending systems involved in aversive behavior. Further use of the procedure should reveal whether, in addition to the ascending midline system shown here, a descending system in control of aversive

Figure 3. Sections through the greatest extent of the lesion for Subjects 2 (upper panel) and 3 (lower panel).

behavior derives from the somewhat more lateral giant-celled nuclei of the medulla and lower pons.

\section{REFERENCES}

Brodal, A. The reticular formation of the brain stem. Anatomical aspects and functional correlations. Edinburgh: Oliver \& Boyd, 1957.

CASEY, K. L. Somatic stimuli, spinal pathways, and size of cutaneous fibers influencing unit activity in the medial medullary reticular formation. Experimental Neurology, 1969, 25, 35-56.

CASEY, K. L. Somatosensory responses of bulboreticular units in awake cat: Relation to escape-producing stimuli. Science, $1971,173,77-80$.

Fifidd, H. L., \& Basbaum, A. I. Brainstem control of spinal pain-transmission neurons. Annual Review of Physiology, 1978, 40, 217-248.

Fifidd, H. L., Wagner, G. M., \& Anderson, S. D. Some properties of spinal neurons projecting to the medial brainstem reticular formation. Experimental Neurology, 1975, 47, 118-134.

Goldman, P. L., Collins, W. F., Taub, A., \& Fitzmartin, J. Evoked bulbar reticular unit activity following delta fiber stimulation of peripheral somatosensory nerve in cat. Experimental Neurology, 1972, 37, 597-606.

Halpern, B. P., \& Halderson, J. D. Modification of escape 
from noxious stimuli after bulbar reticular formation lesions. Behavioral Biology, 1974, 11, 215-229.

KeENE, J. J., \& CASEY, K. L. Excitatory connection from lateral hypothalamic self-stimulation sites to escape sites in medullary reticular formation. Experimental Neurology, 1970, 28, 155-166.

Melzack, R., \& Casey, K. L. Sensory, motivational, and central control determinants of pain. In D. R. Kenshalo (Ed.), The skin senses. Springfield, Ill: Thomas, 1968.

Peterson, B. W. Reticulospinal projections to spinal motor nuclei. Annual Review of Physiology, 1979, 41, 127-140.

Segundo, J. P., Takenaka, T., \& Encabo, H. Somatic sen- sory properties of bulbar reticular neurons. Journal of Neurophysiology, 1967, 30, 1221-1238.

Siegel, J. M., \& McGinty, D. J. Pontine reticular formation neurons: Relationship of discharge to motor activity. Science, 1977, 196, 678-680.

VALVERDE, F. Reticular formation of the albino rat's brain stem. Cytoarchitecture and corticofugal connections. Journal of Comparative Neurology, 1962, 119, 25-49.

(Received for publication May 20, 1980; accepted May 21, 1980.) 